Jurnal Keperawatan Silampari

Volume 2, Nomor 2, Juni 2019

e-ISSN: 2581-1975

p-ISSN: 2597-7482

DOI: https://doi.org/10.31539/jks.v2i2.702

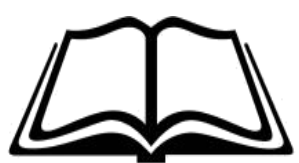

IDMAKNe

\title{
SLOW DEEP BREATHING DAN ALTERNATE NOSTRIL BREATHING TERHADAP PENURUNAN TEKANAN DARAH PADA PASIEN HIPERTENSI
}

\author{
Faradilla Miftah Suranata ${ }^{1}$, Agung Waluyo ${ }^{2}$, Wati Jumaiyah ${ }^{3}$, Dhea Natashia ${ }^{4}$ \\ Program Studi Ilmu Keperawatan, STIKES Muhammadiyah Manado ${ }^{1}$ \\ Program Studi Ners, Universitas Indonesia ${ }^{2}$ \\ Program Studi Magister Keperawatan, Universitas Muhammadiyah Jakarta $a^{3,4}$ \\ faradilla.miftah@yahoo.com ${ }^{1}$
}

\begin{abstract}
ABSTRAK
Tujuan penelitian ini mengetahui efektifitas slow deep breathing dan alternate nostril breathing terhadap penurunan tekanan darah pada pasien dengan hipertensi. Penelitian ini menggunakan desain quasi-experimental dengan pendekatan pretest-posttest group design. Hasil uji Friedman menunjukkan bahwa ada perbedaan tekanan darah sistolik $\left(\mathrm{x}^{2}=34,09 ; \mathrm{p}<0,001\right)$ dan diastolik $\left(\mathrm{x}^{2}=28,74 ; \mathrm{p}<0,001\right)$ pada kelompok intervensi slow deep breathing. Berdasarkan uji post hoc, pengukuran dari waktu ke waktu didapatkan nilai $\mathrm{p}(\mathrm{p}=0,001)$ baik pada tekanan darah sistolik dan diastolik. Sementara itu ada perbedaan tekanan darah pada kelompok alternate nostril breathing sistolik $\left(\mathrm{x}^{2}=15,50\right.$; $\mathrm{p}<0,001)$, diastolik $\left(\mathrm{x}^{2}=17,18 ; \mathrm{p}<0,001\right)$. Uji post hoc didapatkan penurunan tekanan darah sistolik dan diastolik yang signifikan dari masing-masing waktu pengukuran selama periode intervensi dengan masing-masing nilai p 0,005 dan 0,025. Simpulan, dalam penelitian ini yaitu slow deep breathing jauh lebih efektif dalam menurunkan tekanan darah pada pasien hipertensi.
\end{abstract}

Kata Kunci: Alternate Nostril Breathing, Hipertensi, Penurunan Tekanan Darah, Slow Deep Breathing

\begin{abstract}
The purpose of this study is to determine the effectiveness of slow deep breathing and alternate nostril breathing on reducing blood pressure in patients with hypertension. This study uses a quasi-experimental design with a pretest-posttest group design approach. Friedman test results showed that there were differences in systolic blood pressure $(x 2=34.09 ; p<0.001)$ and diastolic $(x 2=28.74 ; p<0.001)$ in the slow deep breathing intervention group. Based on the post hoc test, measurements from time to time obtained $p$ values $(p=0.001)$ for both systolic and diastolic blood pressure. Meanwhile there were differences in blood pressure in the alternate nostril systolic breathing group $(x 2=15.50 ; p<0.001)$, diastolic $(x 2=17.18 ; p<0.001)$. Post hoc test found a significant decrease in systolic and diastolic blood pressure from each measurement time during the intervention period with $p$ values 0.005 and 0.025, respectively. Conclusion, in this study that slow deep breathing is much more effective in reducing blood pressure in hypertensive patients.
\end{abstract}

Keywords: Alternate Nostril Breathing, Hypertension, Decreased Blood Pressure, Slow Deep Breathing 


\section{PENDAHULUAN}

Penyakit tidak menular (PTM) dilaporkan sebagai salah satu penyebab utama kematian di dunia maupun di Indonesia, yang menyumbang prosentase tertinggi angka kematian secara global (WHO, 2017). Pada tahun 2015 khususnya pada negara berkembang, sebesar 17 juta orang dibawah usia 70 tahun telah dilaporkan meninggal akibat penyakit tidak menular (WHO, 2017). Angka mortalitas pada hipertensi yang tinggi dikarenakan penyakit ini dapat berkembang menjadi berbagai gangguan yang beresiko menyebabkan kematian seperti gangguan kardiovaskular, penyakit jantung dan stroke (Riskesdas, 2013). Kematian yang terjadi sebagai akibat dari hipertensi yang terbanyak adalah stroke (51\%) dan penyakit jantung koroner $(45 \%)$ berdasarkan data yang dikumpulkan secara global (WHO, 2013).

Data World Health Organization (WHO) tahun 2011menunjukkan satu milyar orang di dunia menderita hipertensi. Prevalensi hipertensi akan terus meningkat tajam dan diprediksi pada tahun 2025 sebanyak $29 \%$ orang dewasa di seluruh dunia terkena hipertensi (Depkes RI, 2017). Berdasarkan data Riskesdas 2013 di Indonesiaprevalensi penderita hipertensi sebanyak 25,8\% dari total populasi. Di Provinsi Sulawesi Utara, prevalensi penderita hipertensi mencapai $27,1 \%$ dan termasuk ke dalam 10 besar provinsi dengan hipertensi terbanyak di Indonesia (Riskesdas, 2013). Menurut Profil Kesehatan Provinsi Sulawesi Utara Tahun 2016, hipertensi di Sulawesi Utara di alami oleh hampir satu diantara tiga penduduk umur lebih dari 18 tahun dengan prosentase 31,2\% (Dinas Kesehatan Daerah Provinsi Sulawesi Utara, 2016). Di Kabupaten Minahasa tahun 2014, penyakit hipertensi merupakan penyakit menonjol kedua dari sepuluh penyakit yang ada di Minahasa dengan jumlah 32.910 kasus (Dinkes Kabupaten Minahasa, 2014). Data yang diperoleh dari laporan bulanan Puskesmas Koya Kabupaten Minahasa kunjungan pasien dengan hipertensi yaitu pada bulan Maret 2018 sebanyak 321 kunjungan dan bulan April 2018 sebanyak 309 kunjungan.

Tingginya angka prevalensi hipertensi dipicu oleh beberapa faktor, diantaranya stress. Tingginya tingkat stress ini dikarenakan adanya tuntutan pekerjaan, tuntutan ekonomi,dan sebagainya (Riskesdas, 2013). Adanya tingkat stress yang semakin meninggi akibat globalisasisehingga menuntut persaingan dalam segala bidang, dimana stress dapat menyebabkan resistensi vaskular perifer dan curah jantung meningkat sehingga aktifitas sistem saraf simpatis terstimulasi maka tekanan darah meningkat (Black, Hawks, 2014). Apabila dalam kurun waktu yang lama tekanan darah yang tinggi tidak dapat dikendalikan maka akan timbul beberapa komplikasi diantaranya gangguan ginjal, gangguan jantung (penyakit jantung koroner) dan otak (menimbulkan stroke) (Smeltzer, Bare, 2013). Pencegahan komplikasi melibatkan peran mandiri perawatanyang sangat dibutuhkan dalam menerapkan berbagai terapi non farmakologis dalam bidang keperawatan (Muttaqin, 2010).

Terdapat beberapa jenis terapi non farmakologis yang dapat di praktikkan untuk mengendalikan tekanan darah. Salah satu contohnya adalah dengan melakukan manajemen stress seperti teknik relaksasi pernapasan yang dapat memberikan manfaat terapeutik bagi penderita hipertensi (Muttaqin, 2010). Relaksasi merupakan intervensi yang dapat di lakukan pada setiap terapi anti hipertensi dengan mengurangi tekanan gejala yang dirasakan seseorang dalam menghadapi berbagai situasi, menurunkan frekuensi denyut jantung dan tekanan darah serta ketegangan otot jadi menurun (Potter, Perry, 2010). Teknik relaksasi banyak jenisnya, diantaranya teknik relaksasi pernapasan slow deep breathing (Martini, 2011) dan alternate nostril breathing (Telles, et al, 2012). 
Meskipun kedua teknik ini memiliki manfaat yang sama dalam mengurangi stres dan menurunkan tekanan darah bagi seseorang yang mengalami hipertensi, namun kedua teknik ini mempunyai mekanisme kerja awal yang berbeda dalam proses menurunkan tekanan darah. Selain itu masih minimnya penelitian terkait intervensi ini di Indonesia, sehingga belum terevaluasinya efektifitas daripada terapi dalam menurunkan tekanan darah. Oleh karena itu peneliti ingin mengetahui teknik relaksasi yang tergolong dalam terapi non farmakologis yang paling efektif dalam menurunkan tekanan darah. Sehingga tujuan dari penelitian ini adalah untuk mengetahui efektifitas slow deep breathing dan alternate nostril breathing terhadap penurunan tekanan darah pada pasien dengan hipertensi di wilayah kerja Puskesmas Koya Kabupaten Minahasa.

\section{METODE PENELITIAN}

Penelitian ini menggunakan metode kuantitatif dengan rancangan quasiexperimental design dengan pendekatan pretest-posttest group design. Alat pengumpulan data pada penelitian ini berupa kuesioner (meliputi karakteristik responden yaitu usia, jenis kelamin, riwayat merokok, obesitas, jenis obat yang diminum, frekuensi minum obat dan disiplin minum obat), instrumen pengukuran tekanan darah pada masing-masing intervensi dan pengukuran tekanan darah dilakukan dengan menggunakan sphygmomanometer merk $\mathrm{ABN}$ dan stethoscope merek general care.

Populasi dalam penelitian ini adalah pasien dengan hipertensi primer/essensial yang direkrut dari Puskesmas Koya Kabupaten Minahasa. Pasien yang diikutsertakan dalam penelitian ini adalah pasien yang berusia $\geq 18$ tahun, kesadaran compos mentis, mendapatkan pengobatan antihipertensi, berkunjung di Puskesmas Koya Kabupaten Minahasa dan bersedia menjadi responden dan kooperatif. Sementara apabila pasien yang menderita hipertensi sekunder dan terdapat penyakit penyerta (DM, stroke, gangguan pernapasan, gangguan jantung, gangguan ginjal, dislipidemia dan hamil dalam 6 bulan terakhir) maka tidak diikutsertakan dalam penelitian ini. Penentuan besar sampel menggunakan rumus federer didapatkan 32 orang. Antisipasi terjadinya responden droup out $10 \%$ sehingga total sampel menjadi 36 orang. Teknik pengambilan sampel dilakukan dengan cara randomisasi (randomization).

Sebanyak total 38 subjek dikaji kelayakan dalam studi ini (Figure 1). Dimana 36 orang dalam studi setuju untuk berpartisipasi. Responden pada penelitian ini adalah sebanyak 95\%. Partisipan yang telah setuju untuk dijadikan responden menandatangani inform concent. Peneliti menetapkan responden ke dalam kelompok intervensi SDB dan ANB setelah dilakukan pengundian. Penelitian dilakukan dengan mengunjungi rumah responden. Tekanan darah diukur sebanyak 3 kali, yaitu pada baseline (pre test), sesudah 2 minggu diberikan intervensi (post test 1) dan sesudah 4 minggu diberikan intervensi (post test 2). 


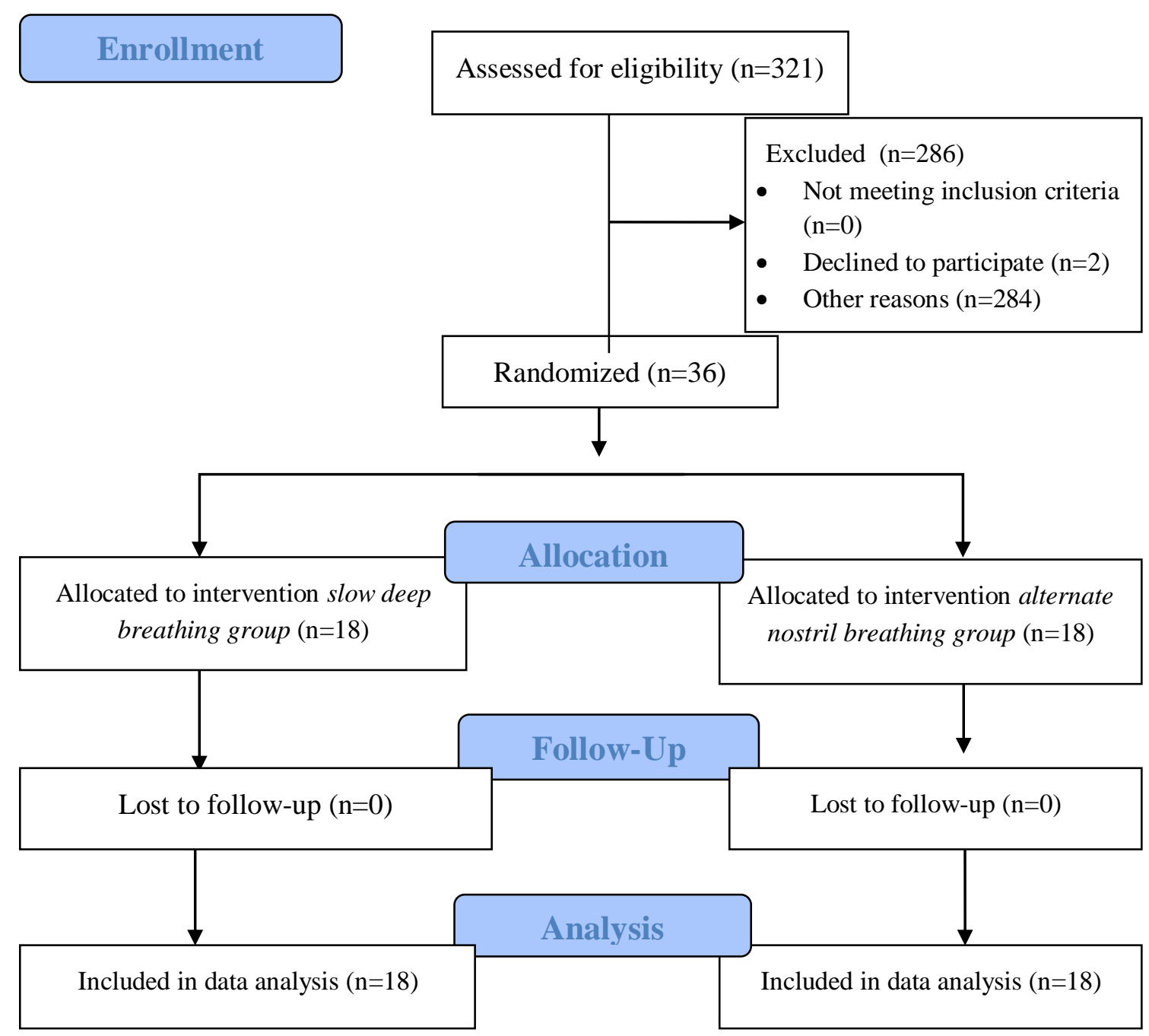

Figure. 1

Flow diagram of trial for two studies

\section{Intervensi Slow Deep Breathing}

Intervensi pada penelitian ini diberikan secara individual dilakukan oleh peneliti selama 4 hari setiap minggu dalam 4 minggu dengan durasi 5 menit. Di implementasikan dalam penelitian ini berupa slow deep breathing. Rekomendasi untuk dilakukan intervensi adalah sehari dua kali, namun dalam penelitian ini dilakukan sehari sekali. Sebelum dilakukan intervensi pasien dianjurkan minum air putih hangat secukupnya dan istirahat dengan posisi duduk selama 10 menit. Kemudian pengukuran tekanan darah baseline dilakukan. Responden dijelaskan mengenai metode dari intervensi. Langkah yang dilakukan yaitu: 1) responden dalam posisi duduk, 2) meletakkan kedua tangan di atas abdomen, 3) menganjurkan bernapas secara perlahan dan dalam melalui hidung, kemudian menarik napas selama 3 detik, responden diminta untuk merasakan pengembangan abdomen saat inspirasi, 4) minta untuk menahan nafas selama kurang lebih 3 detik, 5) responden mengerutkan bibir, kemudian menghembuskan lewat mulut secara perlahan selama 6 detik. Pemberian penelitian ini dilakukan dengan kualifikasi peneliti sebagai mahasiswa magister keperawatan kekhususan keperawatan medikal bedah. 


\section{Intervensi Alternate Nostril Breathing}

Intervensi kedua yang diimplementasikan pada penelitian ini yaitu alternate nostril breathing diberikan secara individual dilakukan oleh peneliti selama 4 hari setiap minggu dalam 4 minggu dengan durasi 5 menit. Rekomendasi dilakukan sehari sekali. Sebelum diberikan intervensi dilakukan pengukuran tekanan darah. Responden dijelaskan mengenai metode dari intervensi. Langkah yang dilakukan yaitu: 1) duduk nyaman dengan punggung lurus, 2) meletakkan jempol kanan pada lubang hidung sebelah kanan, jari manis pada lubang hidung sebelah kiri, dan menarik napas dari kedua lubang hidung, 3) menggunakan lubang jari untuk menutup lubang hidung kanan, buang napas perlahan melalui lubang hidung kiri dan menarik napas dari lubang hidung kiri, 4) menggunakan jari manis untuk menutup lubang hidung kiri, menghembuskan napas pada lubang hidung kanan dan menarik napas pada lubang hidung kanan, 5) lakukan hingga 5 putaran. Pemberian penelitian ini dilakukan dengan kualifikasi peneliti sebagai mahasiswa magister keperawatan kekhususan keperawatan medikal bedah.

Penelitian ini telah diterima dan mengikuti uji etik serta dinyatakan lolos uji kaji etik oleh tim kaji etik penelitian Fakultas Ilmu Keperawatan Universitas Muhammadiyah Jakarta. Data yang telah terkumpul diolah dengan menggunakan aplikasi SPSS versi 22. Deskriptif stastistik dilakukan untuk mengetahui gambaran karakteristik responden dan tekanan darah pada baseline (pre test).

\section{HASIL PENELITIAN Karakteristik Responden}

Tabel. 1

Distribusi Responden Berdasarkan Usia, Jenis Kelamin, Riwayat Merokok, Obesitas, Jenis Obat yang Diminum dan Kedisiplinan Minum Obat dan Tekanan Darah Sebelum diberikan Intervensi $(n=36)$

\begin{tabular}{|c|c|c|c|c|c|c|c|c|c|c|c|}
\hline \multirow{2}{*}{ Karakteristik } & \multicolumn{4}{|c|}{ Slow Deep Breathing } & \multicolumn{4}{|c|}{$\begin{array}{c}\text { Alternate Nostril } \\
\text { Breathing }\end{array}$} & \multicolumn{2}{|c|}{ Total } & \multirow[t]{2}{*}{$\mathrm{p}$ value $e^{\alpha}$} \\
\hline & (f) & $(\%)$ & Mean & $\mathrm{SD}$ & (f) & $(\%)$ & Mean & $\mathrm{SD}$ & (f) & $(\%)$ & \\
\hline Usia & - & - & 60,89 & 7,98 & - & - & 60,78 & 6,49 & - & - & 0,411 \\
\hline TD Sistolik Pre & - & - & 151,11 & 8,32 & - & - & 151,67 & 9,85 & - & - & 0,364 \\
\hline TD Diastolik Pre & - & - & 100 & 7,67 & - & - & 91,11 & 4,71 & - & - & 0,087 \\
\hline Jenis Kelamin & & & & & & & & & & & 0,230 \\
\hline Laki-laki & 8 & 44,4 & - & - & 6 & 33,3 & - & - & 14 & 38,89 & \\
\hline Perempuan & 10 & 55,6 & - & - & 12 & 66,7 & - & - & 22 & 61,11 & \\
\hline Riwayat Merokok & & & & & & & & & & & 0,648 \\
\hline $\mathrm{Ya}$ & 9 & 50 & - & - & 10 & 55,6 & - & - & 19 & 52,78 & \\
\hline Tidak & 9 & 50 & - & - & 8 & 44,4 & - & - & 17 & 47,22 & \\
\hline Obesitas & & & & & & & & & & & 0,119 \\
\hline Tidak obesitas & 15 & 83,3 & - & - & 13 & 72,2 & - & - & 28 & 77,78 & \\
\hline Obesitas & 3 & 16,7 & - & - & 5 & 27,8 & - & - & 8 & 22,22 & \\
\hline Obat yang & & & & & & & & & & & - \\
\hline diminum & 18 & 100 & - & - & 18 & 100 & - & - & 36 & 100 & \\
\hline Amlodipine & 0 & 0 & - & - & 0 & 0 & - & - & 0 & 0 & \\
\hline $\begin{array}{l}\text { Captopril } \\
\text { Amlodipine } \\
\text { dan Captopril }\end{array}$ & 0 & 0 & - & - & 0 & 0 & - & - & 0 & 0 & \\
\hline
\end{tabular}




\begin{tabular}{lcccccccccc} 
Frekuensi Minum & & & & & & & & & & \\
Obat & 18 & 100 & - & - & 18 & 100 & - & - & 18 & 100 \\
$\quad$ 1x sehari & 0 & 0 & - & - & 0 & 0 & - & - & 0 & 0 \\
$\quad \begin{array}{l}\text { 2x sehari } \\
\text { Kedisiplinan }\end{array}$ & & & & & & & & & & \\
Minum Obat & 17 & 94,4 & - & - & 16 & & & & & \\
$\quad$ Ya & 1 & 5,6 & - & - & 2 & 88,9 & - & - & 33 & 91,67 \\
$\quad$ Tidak & & & & & & 11,1 & - & - & 3 & 8,33 \\
Total & 18 & 100 & - & - & 18 & 100 & - & - & 36 & 100 \\
\hline
\end{tabular}

Sumber: Data Primer Tahun 2018

Keterangan:

$\alpha=$ homogenity test (Levene's test)

Berdasarkan tabel 1 menunjukkan bahwa usia rata-rata responden kelompok intervensi slow deep breathing pada penelitian ini $(60,89 \pm 7,98)$ kelompok intervensi alternate nostril breathing $(60,78 \pm 6,49)$. Usia responden pada penelitian ini berada pada rentang 39 sampai dengan 71 tahun. Mayoritas responden pada penelitian ini adalah perempuan $(\mathrm{n}=22 ; 61,11 \%)$, lebih dari $50 \%$ reponden memiliki riwayat merokok $(\mathrm{n}=19 ; 52,78 \%)$ dan memiliki berat badan dalam kategori non obesitas $(\mathrm{n}=28 ; 77,78 \%)$. Seluruh responden pada penelitian ini mendapatkan terapi amlodipine $(n=36 ; 100 \%)$ yang diminum $1 \mathrm{x}$ sehari $(\mathrm{n}=36 ; 100 \%)$. Rata-rata responden menjawab patuh dalam meminum obat $(\mathrm{n}=33 ; 91,67 \%)$. Rata-rata tekanan darah sistolik pada kedua intervensi di atas $150 \mathrm{mmHg}$ yaitu pada kelompok slow deep breathing dengan rata-rata 151,11 $\mathrm{mmHg}(\mathrm{SD}=8,32)$ yang lebih rendah dibandingkan kelompok alternate nostril breathing dengan rata-rata 151,67 ( $\mathrm{SD}=9,85)$. Tekanan darah diastolik pada intervensi SDB $(100 \pm 7,67)$ dan pada intervensi ANB $(91,11 \pm 4,71)$. Tidak ada perbedaan yang ditemukan antara kedua kelompok sebelum dilakukan intervensi $\mathrm{p}$ value $>0,05$ (dalam tabel 1).

\section{Karakteristik Tekanan Darah}

Tabel. 2

Gambaran Perubahan Rata-rata Tekanan Darah Sistolik dan Diastolik Berdasarkan 3 Waktu Pengukuran pada Pasien Hipertensi yang diberikan Slow Deep Breathing dan Alternate Nostril Breathing $(\mathrm{n}=36)$

\begin{tabular}{|c|c|c|c|c|c|c|c|c|}
\hline \multirow{2}{*}{$\begin{array}{l}\text { Kelompok } \\
\text { Intervensi }\end{array}$} & \multirow{2}{*}{$\begin{array}{c}\text { Waktu } \\
\text { Pengukuran }\end{array}$} & \multicolumn{3}{|c|}{ Tekanan Darah Sistolik } & \multicolumn{3}{|c|}{ Tekanan Darah Diastolik } & \multirow[t]{2}{*}{$\mathrm{p}$ value $e^{\alpha}$} \\
\hline & & $\mathrm{n}$ & Mean & SD & $\mathrm{n}$ & Mean & SD & \\
\hline \multirow{3}{*}{$\begin{array}{l}\text { Slow Deep } \\
\text { Breathing }\end{array}$} & $\mathrm{T}_{0}$ & 18 & 151,11 & 8,32 & 18 & 100,00 & 7,67 & 0,364 \\
\hline & $\mathrm{T}_{1}$ & 18 & 141,67 & 8,57 & 18 & 92,22 & 7,32 & 0,326 \\
\hline & $\mathrm{T}_{2}$ & 18 & 132,22 & 7,32 & 18 & 86,67 & 5,94 & 0,917 \\
\hline \multirow{3}{*}{$\begin{array}{l}\text { Alternate Nostril } \\
\text { Breathing }\end{array}$} & $\mathrm{T}_{0}$ & 18 & 151,67 & 9,85 & 18 & 91,11 & 4,71 & 0,087 \\
\hline & $\mathrm{T}_{1}$ & 18 & 147,78 & 6,47 & 18 & 87,22 & 4,61 & 0,056 \\
\hline & $\mathrm{T}_{2}$ & 18 & 143,33 & 6,86 & 18 & 84,44 & 5,11 & 0,698 \\
\hline
\end{tabular}

Sumber: Data Primer Tahun 2018

Keterangan :

$\alpha=$ homogenity test (Levene's test) 
Berdasarkan tabel 2 didapatkan penurunan tekanan darah sistolik sesudah 2 minggu diberikan perlakuan pada kelompok slow deep breathing yang berada pada rentang diatas $141 \mathrm{mmHg}$ dengan rata-rata 141,67 $(\mathrm{SD}=8,57)$ dan pada kelompok alternate nostril breathing berada pada rentang diatas $147 \mathrm{mmHg}$ dengan rata-rata 147,78 (SD=6,47) dibandingkan dengan sebelum diberikan perlakuan. Begitu pula dengan tekanan darah diastolik didapatkan penurunan tekanan darah sesudah 2 minggu diberikan perlakuan pada kelompok slow deep breathing yang berada pada rentang diatas $92 \mathrm{mmHg}$ dengan rata-rata 92,22 ( $\mathrm{SD}=7,32)$ dan pada kelompok alternate nostril breathing berada pada rentang diatas $87 \mathrm{mmHg}$ dengan rata-rata 87,22 (SD=4,61) dibandingkan dengan sebelum diberikan perlakuan. Pada tabel juga menunjukan bahwa terdapat penurunan tekanan darah sistolik sesudah 4 minggu diberikan perlakuan pada kelompok slow deep breathing yang berada pada rentang diatas $132 \mathrm{mmHg}$ dengan rata-rata 132,22 $(\mathrm{SD}=7,32)$ dan pada kelompok alternate nostril breathing berada pada rentang diatas $143 \mathrm{mmHg}$ dengan rata-rata 143,33 (SD=6,86) dibandingkan dengan sesudah 2 minggu diberikan perlakuan. Begitu juga dengan tekanan darah diastolik didapatkan penurunan tekanan darah sesudah 4 minggu diberikan perlakuan pada kelompok slow deep breathing yang berada pada rentang diatas $86 \mathrm{mmHg}$ dengan ratarata 86,67 ( $\mathrm{SD}=5,94)$ dan pada kelompok alternate nostril breathing berada pada rentang diatas $84 \mathrm{mmHg}$ dengan rata-rata $84,44(\mathrm{SD}=5,11)$ dibandingkan dengan sesudah 2 minggu diberikan perlakuan.

\section{Karakteristik Efektifitas Slow Deep Breathing terhadap Tekanan Darah}

Tabel. 3

Pengaruh Intervensi Slow Deep Breathing terhadap Variabel Tekanan Darah Sistolik dan Diastolik Setelah Minggu ke 2 dan Minggu ke 4 pada Pasien dengan Hipertensi $(n=18)$

\begin{tabular}{|c|c|c|c|c|c|c|c|c|}
\hline \multirow{2}{*}{\multicolumn{2}{|c|}{ Variabel }} & \multicolumn{3}{|c|}{ Waktu Pengukuran } & \multirow{3}{*}{$P$ value } & \multirow{3}{*}{$n$} & \multirow{3}{*}{$X^{2}$} & \multirow{3}{*}{$\mathrm{df}$} \\
\hline & & \multirow{2}{*}{$\begin{array}{c}\mathrm{T}_{0} \\
\text { Mean } \pm \mathrm{SD}\end{array}$} & \multirow{2}{*}{$\frac{\mathrm{T}_{1}}{\text { Mean } \pm \mathrm{SD}}$} & \multirow{2}{*}{$\frac{\mathrm{T}_{2}}{\text { Mean } \pm \mathrm{SD}}$} & & & & \\
\hline & & & & & & & & \\
\hline $\begin{array}{l}\text { Tekanan } \\
\text { Sistolik }\end{array}$ & Darah & $151,11 \pm 8,32$ & $141,67 \pm 8,57$ & $132,22 \pm 7,32$ & $0,000^{*}$ & 18 & 34,09 & 2 \\
\hline $\begin{array}{l}\text { Tekanan } \\
\text { Diastolik }\end{array}$ & Darah & $100,00 \pm 7,67$ & $92,22 \pm 7,32$ & $86,67 \pm 5,94$ & $0,000^{*}$ & 18 & 28,74 & 2 \\
\hline
\end{tabular}

Sumber: Data Primer Tahun 2018

Keterangan :

${ }^{*}=\mathrm{p}$ value signifikan

$\mathrm{T}_{0}=$ sebelum dilakukan intervensi;

$\mathrm{T}_{1}=$ sesudah 2 minggu dilakukan intervensi;

$\mathrm{T}_{2}=$ sesudah 4 minggu dilakukan intervensi

Berdasarkan tabel 3 didapatkan hasil bahwa hasil uji nonparametrik Friedman pada kelompok yang diberikan slow deep breathing, nilai signifikasi yang diperoleh adalah $\mathrm{p}<0,001(p<0,05)$, dengan hasil tersebut didapatkan kesimpulan bahwa paling tidak terdapat dua pengukuran tekanan darah sistolik yang berbeda (diantara ketiga waktu pengukuran) $\left(\mathrm{x}^{2}=34,09, \mathrm{p}<0,001\right)$. Sedangkan pada tekanan darah diastolik berdasarkan hasil uji nonparametrik friedman, nilai signifikasi yang diperoleh adalah $\mathrm{p}<0,001(p<0,05)$, dengan hasil tersebut didapatkan kesimpulan bahwa paling tidak terdapat dua pengukuran tekanan darah diastolik yang berbeda (diantara ketiga waktu pengukuran) $\left(x^{2}=28,74, p<0,001\right)$. 
Tabel. 4

Hasil Uji Friedman dengan Post Hoc Wilcoxon Tekanan Darah Sistolik dan Diastolik pada Responden yang Diberikan Intervensi Slow Deep Breathing $(\mathrm{n}=18)$

\begin{tabular}{ccccc}
\hline \multirow{2}{*}{ Waktu Pengukuran } & \multicolumn{2}{c}{ Tekanan Darah Sistolik } & \multicolumn{2}{c}{ Tekanan Darah Diastolik } \\
\cline { 2 - 5 } & $\begin{array}{c}\text { Median (Minimum - } \\
\text { Maximum) }\end{array}$ & P value & $\begin{array}{c}\text { Median (Minimum - } \\
\text { Maximum) }\end{array}$ & P value \\
\hline $\mathrm{T}_{0}-\mathrm{T}_{1}$ & $150(140-170)$ & $0,001^{*}$ & $100(90-110)$ & $0,001^{*}$ \\
$\mathrm{~T}_{0}-\mathrm{T}_{2}$ & $140(130-160)$ & $0,001^{*}$ & $90(80-100)$ & $0,001^{*}$ \\
$\mathrm{~T}_{1}-\mathrm{T}_{2}$ & $130(120-140)$ & $0,001^{*}$ & $90(80-100)$ & $0,002^{*}$ \\
\hline
\end{tabular}

Sumber: Data Primer Tahun 2018

Keterangan :

$*$ p value signifikan

Uji Friedman. Nilai p tekanan darah sistolik pada post hoc Wilcoxon: Sebelum vs Sesudah 2 Minggu $<0,001$; Sebelum vs Sesudah 4 Minggu <0,001; Sesudah 2 Minggu vs Sesudah 4 Minggu <0,001.

Uji Friedman. Nilai p tekanan darah diastolik pada post hoc Wilcoxon: Sebelum vs Sesudah 2 Minggu $<0,001$; Sebelum vs Sesudah 4 Minggu <0,001; Sesudah 2 Minggu vs Sesudah 4 Minggu <0,002.

Berdasarkan tabel 4 yang dilanjutkan uji post hoc Wilcoxon diperoleh nilai $\mathrm{p}=0,001$ untuk perbandingan semua kelompok tekanan darah sistolik. Selisih antar pengukuran sebelum hingga 4 minggu sesudah diberikan terapi yaitu $20 \mathrm{mmHg}$. Berdasarkan uji post hoc wilcoxon diperoleh hasil bahwa terdapat penurunan dari waktu ke waktu $\left(\mathrm{T}_{0}\right.$ ke $\mathrm{T}_{1}$ dan ke $\mathrm{T}_{2}$ ) yang berarti dari masing-masing waktu pengukuran terdapat penurunan tekanan darah sistolik yang signifikan secara statistik. Pada tabel menunjukkan bahwa tekanan darah diastolik post hoc Wilcoxon diperoleh nilai $\mathrm{p}=0,001$ untuk perbandingan kelompok sebelum dan sesudah 2 minggu diberikan terapi dan $\mathrm{p}=0,002$ untuk perbandingan sesudah 4 minggu diberikan terapi. Selisih antar pengukuran sebelum hingga 4 minggu sesudah diberikan terapi yaitu $10 \mathrm{mmHg}$. Berdasarkan uji post hoc wilcoxon diperoleh hasil bahwa terdapat penurunan dari waktu ke waktu $\left(\mathrm{T}_{0}\right.$ ke $\mathrm{T}_{1}$ dan ke $\left.\mathrm{T}_{2}\right)$ yang berarti dari masing-masing waktu pengukuran terdapat penurunan tekanan darah diastolik yang signifikan secara statistik.

\section{Karakteristik Alternate Nostril Breathing terhadap Tekanan Darah}

Tabel. 5

Pengaruh Intervensi Alternate Nostril Breathing terhadap Variabel Tekanan Darah Sistolik dan Diastolik Setelah Minggu ke 2 dan Minggu ke 4 pada Pasien dengan Hipertensi $(n=18)$

\begin{tabular}{|c|c|c|c|c|c|c|c|c|}
\hline & & \multicolumn{3}{|c|}{ Waktu Pengukuran } & \multirow[b]{2}{*}{ Pvalue } & \multirow[b]{2}{*}{$n$} & \multirow[b]{2}{*}{$X^{2}$} & \multirow[b]{2}{*}{$\mathrm{df}$} \\
\hline \multicolumn{2}{|c|}{ Variabel } & $\mathrm{T}_{0}$ & $\mathrm{~T}_{1}$ & $\mathrm{~T}_{2}$ & & & & \\
\hline \multirow{2}{*}{$\begin{array}{l}\text { Tekanan } \\
\text { Sistolik } \\
\text { Tekanan } \\
\text { Diastolik }\end{array}$} & Darah & $151,67 \pm 9,85$ & $147,78 \pm 6,47$ & $143,33 \pm 6,86$ & $0,000^{*}$ & 18 & 15,50 & 2 \\
\hline & Darah & $91,11 \pm 4,71$ & $87,22 \pm 4,61$ & $84,44 \pm 5,11$ & $0,000^{*}$ & 18 & 17,18 & 2 \\
\hline
\end{tabular}

\section{Sumber: Data Primer Tahun 2018}

Keterangan :

${ }^{*}=\mathrm{p}$ value signifikan

$\mathrm{T}_{0}=$ sebelum dilakukan intervensi;

$\mathrm{T}_{1}=$ sesudah 2 minggu dilakukan intervensi;

$\mathrm{T}_{2}=$ sesudah 4 minggu dilakukan intervensi 
Tabel 5 menunjukkan bahwa hasil uji nonparametrik friedman pada kelompok yang diberikan alternate nostril breathing, nilai signifikasi yang diperoleh adalah $\mathrm{p}<0,001(p<0,05)$, dengan hasil tersebut didapatkan kesimpulan bahwa paling tidak terdapat dua pengukuran tekanan darah sistolik yang berbeda (diantara ketiga waktu pengukuran) $\left(x^{2}=15,50, p<0,001\right)$. Sedangkan pada tekanan darah diastolik berdasarkan hasil uji nonparametrik Friedman, nilai signifikasi yang diperoleh adalah $\mathrm{p}<0,001$ $(p<0,05)$, dengan hasil tersebut didapatkan kesimpulan bahwa paling tidak terdapat dua pengukuran tekanan darah diastolik yang berbeda (diantara ketiga waktu pengukuran) $\left(\mathrm{x}^{2}=17,18, \mathrm{p}<0,001\right)$.

Tabel. 6

Hasil Uji Friedman dengan Post Hoc Wilcoxon Tekanan Darah Sistolik dan Diastolik pada Responden yang Diberikan Intervensi Alternate Nostril Breathing $(\mathrm{n}=18)$

\begin{tabular}{ccccc}
\hline \multirow{2}{*}{ Waktu Pengukuran } & \multicolumn{2}{c}{ Tekanan Darah Sistolik } & \multicolumn{2}{c}{ Tekanan Darah Diastolik } \\
\cline { 2 - 5 } & $\begin{array}{c}\text { Median (Minimum - } \\
\text { Maximum) }\end{array}$ & P value & $\begin{array}{c}\text { Median (Minimum - } \\
\text { Maximum) }\end{array}$ & P value \\
\hline $\mathrm{T}_{0}-\mathrm{T}_{1}$ & $150(140-170)$ & $0,001^{*}$ & $100(90-110)$ & $0,001^{*}$ \\
$\mathrm{~T}_{0}-\mathrm{T}_{2}$ & $140(130-160)$ & $0,001^{*}$ & $90(80-100)$ & $0,001^{*}$ \\
$\mathrm{~T}_{1}-\mathrm{T}_{2}$ & $130(120-140)$ & $0,001^{*}$ & $90(80-100)$ & $0,002^{*}$ \\
\hline
\end{tabular}

Sumber: Data Primer Tahun 2018

Keterangan :

$*$ p value signifikan

Uji Friedman. Nilai p tekanan darah sistolik pada post hoc Wilcoxon: Sebelum vs Sesudah 2 Minggu $<0,001$; Sebelum vs Sesudah 4 Minggu <0,001; Sesudah 2 Minggu vs Sesudah 4 Minggu <0,001.

Uji Friedman. Nilai p tekanan darah diastolik pada post hoc Wilcoxon: Sebelum vs Sesudah 2 Minggu $<0,001$; Sebelum vs Sesudah 4 Minggu <0,001; Sesudah 2 Minggu vs Sesudah 4 Minggu <0,002.

Berdasarkan tabel 6 diperoleh nilai $\mathrm{p}=0,138$ untuk tekanan darah sistolik sebelum diberikan terapi alternate nostril breathing, nilai $\mathrm{p}=0,001$ untuk tekanan darah sistolik sesudah 2 minggu diberikan terapi dan nilai $\mathrm{p}=0,005$ untuk tekanan darah sistolik sesudah 4 minggu di berikan terapi. Selisih antar pengukuran sebelum hingga 4 minggu sesudah diberikan terapi yaitu $10 \mathrm{mmHg}$. Berdasarkan uji post hoc wilcoxon diperoleh hasil bahwa terdapat penurunan dari waktu ke waktu $\left(\mathrm{T}_{0}\right.$ ke $\mathrm{T}_{1}$ dan ke $\left.\mathrm{T}_{2}\right)$ yang berarti dari masing-masing waktu pengukuran terdapat penurunan tekanan darah sistolik yang signifikan secara statistik. tekanan darah diastolik post hoc wilcoxon diperoleh nilai $\mathrm{p}=0,008$ untuk tekanan darah diastolik sebelum diberikan terapi alternate nostril breathing, nilai $\mathrm{p}=0,001$ untuk tekanan darah diastolik sesudah 2 minggu diberikan terapi alternate nostril breathing dan nilai $\mathrm{p}=0,025$ untuk tekanan darah diastolik sesudah 4 minggu diberikan terapi alternate nostril breathing. Selisih antar pengukuran sebelum hingga 4 minggu sesudah diberikan terapi yaitu $10 \mathrm{mmHg}$. Berdasarkan uji post hoc wilcoxon diperoleh hasil bahwa terdapat penurunan dari waktu ke waktu ( $\mathrm{T}_{0}$ ke $\mathrm{T}_{1}$ dan ke $\mathrm{T}_{2}$ ) yang berarti dari masing-masing waktu pengukuran terdapat penurunan tekanan darah diastolik yang signifikan secara statistik.

\section{PEMBAHASAN}

Hasil penelitian ini menunjukkan bahwa usia rata-rata pada kelompok intervensi slow deep breathing setara dengan kelompok intervensi alternate nostril breathing yaitu 61 tahun dimana usia tersebut berada pada kelompok usia lansia (elderly) berdasarkan WHO tahun 2016. Usiarespondentermuda adalah 39 tahun dan tertua adalah 71 tahun. Karakteristik usia responden pada penelitian ini sesuai dengan penelitian Tuminah 
(2009) dalam Mohd, Arifin et al, (2016) dimana prevalensi hipertensi sebanyak 30\% dimulai terjadi pada kelompok usia 25-44 tahun dan meningkat seiring bertambahnya usia yaitu dengan angka kejadian lebih dari 50\% pada usia diatas 60 tahun. Keadaan ini sejalan dengan trend kejadian hipertensi dimana hipertensi terjadipada 60-80\% dari populasi lansia (Mateos-C'Aceres PJ et al, 2012) dan angka kejadian hipertensi di Indonesia paling banyak terjadi pada umur 55-64 tahun (17,2\%) (Depkes RI, 2017). Penuaan mempengaruhi baroreseptor yang terlibat dalam pengaturan tekanan darah serta kelenturan arteri (Le Mone et al, 2016). Ketika arteri menjadi kurang lentur, tekanan dalam pembuluh darah mengalami peningkatan, yang tampak sebagai peningkatan bertahap tekanan sistolik seiring penuaan.

Berdasarkan hasil penelitian ini menunjukkan bahwa jenis kelamin terbanyak pada responden adalah perempuan baik pada kelompok intervensi slow deep breathing sebanyak 10 orang $(55,6 \%)$ dan kelompok intervensi alternate nostril breathing sebanyak 12 orang $(66,7 \%)$. Faktor jenis kelamin berpengaruhpada terjadinya hipertensi, dimana pada usia muda dibawah 60 tahun, pria lebih banyak yang menderita hipertensi dibandingkan wanita. Pria diduga memiliki gaya hidup yang cenderung dapat meningkatkan tekanan darah dibanding wanita. Namun setelah memasuki menopause, prevalensi hipertensi pada wanita meningkat (Depkes RI, 2006 dalam Mohd. Arifin, et al, 2016). Dalam penelitian ini, sebagian besar perempuan sudah memasuki masa menopause $(55,6 \%)$ dilihat dari keseluruhan jumlah responden pada kedua kelompok intervensi. Hasil penelitian ini sejalan dengan penelitian Kurniasih dan Setiawan (2011) dimana prevalensi penderita hipertensi terbanyak adalah wanita yang sudah memasuki masa menopause $(75,7 \%)$. Resiko hipertensi pada perempuan meningkat seiring bertambahnya usia. Dengan pertambahan usia maka akan terjadi pula penurunan dari kadar hormon estrogen, terlebih lagi setelah terjadinya menopause pada perempuan. Hormon estrogen yang salah satu fungsinya meningkatkan HDL dan menurunkan LDL dalam darah. Ketika terjadi penurunan hormon tersebut maka yang akan terjadi sebaliknya, perempuan akan cenderung memiliki LDL yang tinggi, dan akan meningkatkan viskositas darah, sehingga beban jantung untuk memompakan darah pun akan meningkat, yang pada akhirnya akan mencetuskan terjadinya hipertensi (Anggraini et al, 2009).

Hasil penelitian menunjukkan bahwa lebih dari setengah jumlah responden pada kedua kelompok intervensi memiliki riwayat merokok yaitu masing-masing sebanyak $50 \%$ pada kelompok intervensi slow deep breathing $(\mathrm{n}=9)$ dan 55,6\% pada kelompok intervensi alternate nostril breathing $(\mathrm{n}=10)$. Merokok adalah salah satu faktor resiko terjadinya hipertensi dan jika dilihat dari karakteristik usia, kategori usia responden pada penelitian ini terjadi dalam kelompok lansia dimana kedua faktor tersebut dapat meningkatkan probabilitas kejadian hipertensi. Menurut penelitian Lewa dkk, (2010) lansia yang memiliki kebiasaan merokok akan meningkatkan risiko kejadian Hipertensi Sistolik Terisolasi (HST) 3 kali lebih besar dibandingkan dengan lansia yangtidak merokok. Kebiasaan merokok bisameningkatkan resiko tekanan darah tinggi (hipertensi) karena nikotin dan karbondioksida yang terkandung dalam rokok bisa mengakibatkan lapisan endotel pembuluh darah arteri rusak, elastisitas pembuluh darah berkurang sehingga pembuluh darah menjadi kaku dan mengganggu aliran darah sehingga menyebabkan tekanan darah meningkat (Singalingging, 2011; Anggara, Prayitno, 2012). Nikotin dapat meningkatkan jumlah nadi dan menghasilkan vasokontriksi perifer yang mana tekanan darah dapat meningkat dalam waktu pendek atau setelah merokok. Selain itu, menurut literatur, nikotin juga dapat meningkatkan 
norepineprin dan katekolamin sehingga kerja jantung meningkat dan menyebabkan peningkatan tekanan darah.

Berdasarkan hasil penelitian ini mayoritas responden memiliki berat badan pada kategori non obesitas baik pada kelompok intervensi slow deep breathing $(\mathrm{n}=15$; 83,5\%) maupun kelompok intervensi alternate nostril breathing $(\mathrm{n}=13 ; 72,2)$. Literatur mengatakan bahwa berat badan menjadi faktor determinan pada tekanan darah pada beberapa kelompok etnik (Kumar, Vinay et al, 2015). Namun pada beberapa penelitian juga menyatakan bahwa peningkatan berat badan tidak memiliki kaitan dengan kejadian hipertensi (Siringiringo, 2013; Mohd. Arifin et al, 2016). Penilaian status gizi tidak hanya dilihat berdasarkan berat badan total, beberapa pengukuran seperti skin fold tes dan abdominal fat juga mempengaruhi kandungan zat didalam tubuh yang dapat mempengaruhi perubahan fisiologis pada proses metabolisme. Kegemukan sentral (deposit sel lemak di abdomen), ditentukan oleh peningkatan perbandingan pinggang ke panggul, mempunyai korelasi lebih kuat dengan hipertensi dibanding dengan indeks massa atau ketebalan lipatan kulit (LeMone et al, 2016). Selain itu, tingginya asupan kalori, lemak total, lemak jenuh, gula dan garam juga dapat menimbulkan hiperlipidemia, resistensi insulin yang menjadi faktor resiko terjadinya hipertensi (Price, Wilson, 2013). Faktor-faktor psikologis seperti stress juga menjadi faktor resiko terjadinya hipertensi. Dengan demikian, hal tersebut menjelaskan walaupun karakteristik pada penelitian ini berada pada kategori non obesitas, hipertensi bisa disebabkan oleh faktor lain yang belum atau tidak diteliti oleh peneliti.

Berdasarkan hasil penelitian tekanan darah sistolik dari kedua kelompok intervensi sebelum diberikan intervensi berada pada rentang diatas $150 \mathrm{mmHg}$ yaitu pada kelompok slow deep breathing dengan rata-rata $151,11 \mathrm{mmHg}(\mathrm{SD}=8,32)$ yang lebih rendah dibandingkan kelompok alternate nostril breathing dengan rata-rata 151,67 ( $\mathrm{SD}=9,85)$. Sedangkan tekanan darah diastolik dari kelompok slow deep breathing berada pada rentang diatas $100 \mathrm{mmHg}$ dengan rata-rata 100,00 ( $\mathrm{SD}=7,67)$ dan pada kelompok alternate nostril breathing berada pada rentang diatas $91 \mathrm{mmHg}$ dengan rata-rata 91,11 ( $\mathrm{SD}=4,71)$ yang didapatkan sebelum diberikan perlakuan. Setelah 2 dan 4 minggu diberikan perlakuan didapatkan penurunan tekanan darah sistolik dari wakut ke waktu. Hal ini sejalan dengan penelitian Gusmiah (2015) dan Kuni (2017) bahwa didapatkan perbedaan rata-rata tekanan darah sebelum dan sesudah diberikan intervensi slow deep breathing dan alternate nostril breathing.

\section{Efektifitas Slow Deep Breathing terhadap Tekanan Darah}

Berdasarkan hasil penelitian ini didapatkan kesimpulan bahwa terjadi penurunan tekanan darah sistolik $\left(\mathrm{x}^{2}=34,088 ; \mathrm{p}<0,001\right)$ dan diastolik $\left(\mathrm{x}^{2}=28,737 ; \mathrm{p}<0,001\right)$ pada beberapa waktu pengukuran (time measurement) setelah dilakukan intervensi slow deep breathing. Time effect measurement dievaluasi pada uji lanjutan post hoc wilcoxon untuk melihat signifikansi perubahan tekanan darah dari waktu ke waktu. Terdapat penurunan tekanan darah sistolik $\left(\mathrm{T}_{0}-\mathrm{T}_{2}=20 \mathrm{mmHg} ; \mathrm{p}=0,001\right)$ dan tekanan darah diastolik $\left(\mathrm{T}_{0}-\mathrm{T}_{2}=10 \mathrm{mmHg} ; \mathrm{p}=0,002\right)$. Dengan demikian disimpulkan bahwa slow deep breathing efektif dalam menurunkan tekanan darah pasien dengan hipertensi, dimana dalam waktu 2 minggu setelah intervensi dilakukan sudah terdapat penurunan tekanan darah. Penurunan tekanan darah juga terjadi pada 1 bulan dilakukan intervensi. Penelitian ini sejalan dengan penelitian sebelumnya yang menyimpulkan penurunan tekanan darah yang signifikan setelah dilakukan slow breathing oleh Tomas Drozdz et $a l$, (2015) dimana dari hasil penelitian didapatkan $p$ value $0,002(<0,05)$. Penurunan 
tekanan darah sistolik juga ditemukan pada penelitian sebelumnya yang menggunakan intervensi latihan pernapasan (Li Changjun et al, 2018; Fadli, 2015).

Teknik slow deep breathing dapat memberikan pengaruh terhadap tekanan darah karena ekshalasi yang panjang dari pada metode latihan slow deep breathing akan menyebabkan tekanan intratoraks di paru meningkat selama inspirasi sehingga membuat peningkatan kadar oksigen di dalam jaringan. Refleks kemoreseptor yang banyak terdapat di badan karotis, badan aorta dan sedikit pada rongga toraks dan paru menjadi teraktivasi. Kemudian membawa sinyal saraf menuju pusat pernapasan yaitu di medula oblongata. Sehingga aktivitas kerja saraf parasimpatis meningkat dan menurunkan aktivitas kerja saraf simpatis sehingga akan menyebabkan tekanan darah menurun (Joohan, 2000 dalam Wahyuni et al, 2015).

Peningkatan tekanan intratoraks di paru tidak hanya menyebabkan peningkatan oksigen jaringan, namun juga menyebabkan tekanan di vena sentral menurun yang mengakibatkan aliran balik vena dan peningkatan volume vena sentral sehingga curah jantung dan stroke volume akan meningkat di jantung kiri. Refleks baroreseptor yang ada di arkus aorta dan arteri karotis interna terstimulasi. Kemudian impuls di kirimkan ke traktus solitarius medulla oblongata. Di medulla oblongata membuat pusat simpatis terangsang berikatan dengan $\alpha 1$ reseptor sehingga menurunkan keluaran saraf simpatis. Maka vasodilatasi pada vena dan arteriol sehingga resistensi perifer menurun maka tekanan darah menurun. Selain itu impuls yang dikirimkan menghambat vasokonstriktor di medulla, maka pusat parasimpatis vagus terangsang. Vasodilatasi vena dan arteriol di seluruh sistem perifer jantung terjadi sehingga keluaran saraf parasimpatis meningkat sehingga membuat frekuensi jantung berkurang dan merangsang ventrikel untuk menurunkan kontraksi yang menimbulkan efek curah jantung menurun sehingga tekanan darah menurun (Black, Hawk, 2014; Guyton, Hall, 2016 \& Sheerwood, 2016).

\section{Efektifitas Alternate Nostril Breathing terhadap Tekanan Darah}

Berdasarkan hasil penelitian ini didapatkan kesimpulan bahwa terjadi penurunan tekanan darah sistolik $\left(X^{2}=15,500 ; p<0,001\right)$ dan diastolik $\left(X^{2}=17,176 ; p<0,001\right)$ pada beberapa waktu pengukuran (time measurement) setelah dilakukan intervensi alternate nostril breathing. Time effect measurement dievaluasi pada uji lanjutan post hoc wilcoxon untuk melihat signifikansi perubahan tekanan darah dari waktu ke waktu. Terdapat penurunan tekanan darah sistolik $\left(\mathrm{T}_{0}-\mathrm{T}_{2}=10 \mathrm{mmHg} ; \mathrm{p}=0,005\right)$ dan tekanan darah diastolik $\left(\mathrm{T}_{0}-\mathrm{T}_{2}=10 \mathrm{mmHg} ; \mathrm{p}=0,025\right)$. Dengan demikian disimpulkan bahwa alternate nostril breathing efektif dalam menurunkan tekanan darah pasien dengan hipertensi, dimana dalam waktu 4 minggu setelah intervensi dilakukan sudah terdapat penurunan tekanan darah. Penelitian ini sejalan dengan penelitian sebelumnya yang menyimpulkan terjadi penurunan tekanan darah sistolik dan diastolik setelah dilakukan intervensi alternate nostril breathing (Telles et al, 2012; Kuni, 2017). Dari penelitian lain yang serupa, diperoleh informasi bahwa penurunan tekanan darah terjadi setelah intervensi alternate nostril breathing yang dilakukan paling sedikit dalam waktu 4 minggu hingga 8 minggu (Narayan Sinha, 2013; Dhungel Upadhyay et.al, 2013; Dhanvijay et al, 2015).

Teknik alternate nostril breathing dapat memberikan pengaruh terhadap tekanan darah yaitu karena adanya hubungan bermakna antara siklus nasal, dominasi serebral dan aktivitas otonom dimana siklus nasal ini berhubungan dengan dominasi serebral. Ketika salah satu lubang hidung mendominasi maka hemisfer kontra lateral akan teraktivasi. Bernapas melalui nostril kanan yang melalui spinal kanan dan berhubungan 
dengan hemisfer serebral kiri menyebabkan peningkatan stimulasi sistem saraf simpatik untuk dapat menurunkan fungsinya dimana saraf simpatik dapat membuat vena dan arteriol menagalami vasokonstriksi. Sementara itu, pernapasan melalui nostril kiri yang melalui spinal kiri dan berhubungan langsung dengan hemisfer serebral kanan yang merangsang kerja saraf parasimpatik menjadi meningkat, sehingga tubuh akan mengalami relaksasi. Vasodilatasi vena dan arteriol di seluruh sistem perifer jantung juga terjadi sehingga keluaran saraf parasimpatis meningkat sehingga membuat frekuensi jantung berkurang dan merangsang ventrikel untuk menurunkan kontraksi yang menimbulkan efek curah jantung menurun sehingga tekanan darah menurun (Dhungel, Sohal, 2013; Black, Hawk, 2014).

\section{Efektifitas Slow Deep Breathing dan Alternate Nostril Breathing terhadap Penurunan Tekanan Darah}

Berdasarkan hasil uji friedman pada kedua intervensi peneliti menilai bahwa slow deep breathing lebih efektif dibandingkan alternate nostril breathing dalam menurunkan tekanan darah. Hal tersebut disimpulkan dari melihat besarnya selisih dan $\mathrm{p}$ value dari masing-masing intervensi dimana $\mathrm{p}$ value pada intervensi slow deep breathing dan alternate nostril breathing setara dengan hasil tekanan darah sistolik $\mathrm{p}<0,001$ dan diastolik $\mathrm{p}<0,001$. Sedangkan selisih tekanan darah dari time effect measurement berdasarkan hasil post hoc wilcoxon pada intervensi slow deep breathing sedikit lebih besar dibandingkan dengan intervensi alternate nostril breathing dimana selisih penurunan tekanan darah sistolik $20 \mathrm{mmHg}$ dan tekanan darah diastolik 10 $\mathrm{mmHg}$ (intervensi slow deep breathing), dan pada intervensi alternate nostril breathing didapatkan selisih penurunan tekanan darah sistolik $10 \mathrm{mmHg}$ dan tekanan darah diastolik $10 \mathrm{mmHg}$. Peneliti berasumsi hal ini dapat disebabkan beberapa faktor antara lain karena variabel confounding pada kelompok alternate nostril breathing berbeda bila dibandingkan dengan kelompok slow deep breathing dimana pada kelompok alternate nostril breathing didapatkan prosentase riwayat merokok dan obesitas yang lebih besar dibandingkan pada kelompok slow deep breathing. Variabel confounding tersebut dapat mempengaruhi perbedaan penurunan tekanan darah. Sehingga dapat ditarik kesimpulan bahwa, intervensi slow deep breathing lebih efektif untuk menurunkan tekanan darah sistolik dan diastolik pada pasien dengan hipertensi.

\section{SIMPULAN}

Intervensi slow deep breathing dan alternate nostril breathing dilakukan pada responden dengan hipertensi pada penelitian ini. Disimpulkan bahwa dengan rutin melakukan terapi pernapasan dapat menurunkan tekanan darah pada hipertensi, dimana slow deep breathing jauh lebih efektif dalam menurunkan tekanan darah. Ini menjelaskan bahwa perawat dapat berperan dalam mengendalikan tekanan darah pasien hipertensi dengan terapi nonfarmakologis khususnya terapi pernapasan.

\section{SARAN}

Penelitian selanjutnya disarankan menggunakan desain randomized clinical trial (RCT) dengan pemilihan sampel yang lebih banyak. Kemudian pengujian antara variabel tekanan darah pada kedua kelompok intervensi tidak dilakukan, maka dapat di lanjutkan dengan menggunakan uji analisa General Linear Model Repeated Measure (GLMRM) bila data berdistribusi normal. Generalized Estimating Equation (GEE) dilakukan bila tidak berdistribusi normal. Slow deep breathing dan alternate nostril 
breathing dapat dijadikan salah satu intervensi keperawatan mandiri pada pasien dengan hipertensi. Namun demikian untuk dapat melaksanakan slow deep breathing dan alternate nostril breathing, perawat harus dapat melaksanakannya dengan benar sehingga diperlukan peningkatan pengetahuan dan ketrampilan dalam pelaksanaan latihan tersebut.

\section{DAFTAR PUSTAKA}

Anggara, F. H. D., \& Prayitno., P. (2012). Faktor-Faktor yang Berhubungan dengan Tekanan Darah di Puskesmas Telaga Murni, Cikarang Barat Tahun 2012. Jurnal Ilmiah Kesehatan, 5(1). Diakses pada tanggal 27 Juli 2018

Anggraini, A. D., Waren, S., Situmorang, E., Asputra, H., \& Siahaan, SS. (2009). Faktor-Faktor yang Berhubungan dengan Kejadian Hipertensi pada Pasien yang Berobat di Poliklinik Dewasa Puskesmas Bangkinang Periode Januari Sampai Juni 2008. Fakultas Kesehatan. Universitas Riau. Files of DrsMed-FK UNRI : 141. Diambil kembali dari https://yayanakhyar.files.wordpress.com/2009/02/filesof-drsmed-faktor-yang-berhubungan-dengan-kejadian-hipertensi.pdf pada tanggal 27 Juli 2018

Arifin, M. H., Weta, W., Ayu, R. (2016). Faktor-Faktor yang Berhubungan dengan Kejadian Hipertensi pada Kelompok Lanjut Usia di Wilayah Kerja UPT Puskesmas Petang I Kabupaten Badung tahun 2016. E-Jurnal Medika, 5(7). https://ojs.unud.ac.id/index.php/eum/article/view/21559

Black, J. M., \& Hawks, J. H. (2014). Keperawatan Medikal Bedah: Manajemen Klinis untuk Hasil yang Diharapkan. Buku 3. Edisi 8. Jakarta: Salemba Medika

Changjun, L. (2018). Effects of Slow Breathing Rate on Heart Rate Variability and Arterial Baroreflex Sensitivity in Essential Hypertension. Medicine Journal. Diakses pada tanggal 5 Agustus 2018

Depkes RI. (2017). Sebagian Besar Penderita Hipertensi Tidak Menyadarinya. Diambil kembali dari http://www.depkes.go.id/article/view/17051800002/sebagian-besarpenderita-hipertensi-tidak-menyadarinya.html pada tanggal 12 Agustus 2018

Dhanvijay, A. (2015). Alternate Nostril Breathing and Autonomic Function in Healthy Young Adults. www.iosrjournals.org. DOI: 10.9790/0853-14366265: Diakses pada tanggal 2 Agustus 2018

Dhungel, U., Sohal. (2013). Physiology of Nostril Breathing Exercises and Its Probable Relation with Nostril and Cerebral Dominance: A Theoretical Research on Literature. Janaki Medical College Journal of Medical Sciences, 1(1),47. https://www.nepjol.info/index.php/JMCJMS/article/viewFile/7885/6431: Diakses pada tanggal 26 Februari 2018

Dinas Kesehatan Daerah Provinsi Sulawesi Utara. (2016). Profil Kesehatan Provinsi Sulawesi Utara. Diambil kembali dari Dinas Kesehatan Provinsi Sulawesi Utara: http://dinkes.sulutprov.go.id/wp-content/uploads/2016/11/Buku-Profil-KesehatanSulut-2016.pdf pada tanggal 14 Februari 2018

Fadli. (2015). Pengaruh Latihan Nafas Dalam terhadap Sensitivitas Barorfleks Arteri pada Klien Gagal Jantung Kongestif di RSUD Labuang Baji Kota Makassar. Tesis. Diambil kembali dari Perpustakaan FIK UMJ. http://www.perpus.fikumj.ac.id/repository//manuskrip\%20fadli.pdf pada tanggal 29 Oktober 2017

Gusmiah, T. (2015). Penurunan Tekanan Darah melalui Latihan Slow Deep Breathing pada Hipertensi Primer. Tesis. Diambil kembali dari Perpustakaan FIK UMJ 
http://www.perpus.fikumj.ac.id/repository//Manuskrip\%20tisa.pdf pada tanggal 2 Maret 2018

Guyton, A. C., \& Hall, J. E. (2016). Buku Ajar Fisiologi Kedokteran. Edisi Revisi Berwarna ke 12. Penterjemah: Ernita I, Ibrahim Ilyas. Indonesia: Elsevier

Kumar, Vinay., Abbas K.Abdul., Aster C. Jon. (2015). Buku Ajar: Patologi Robbins. Jakarta: EGC

Kuni, S. (2017). Efektifitas Teknik Pernapasan Nostril Alternatif terhadap Penurunan Tekanan Darah pada Pasien Hipertensi di Ruang Rawat Inap RSI Sultan Agung Semarang. Diambil kembali dari http://repository.unissula.ac.id/7280/ pada tanggal 3 Agustus 2017

Kurniasih, I. \& Setiawan, M., R. (2011). Analisis Faktor Resiko Kejadian Hipertensi di Puskesmas Srondol Semarang Periode Bulan September-Oktober 2011. Jurnal Kedokteran Muhammadiyah, 1(2)

LeMone. (2016). Buku Ajar Keperawatan Medikal Bedah: Gangguan Respirasi dan Gangguan Muskuloskeletal. Volume 4. Edisi 5. Jakarta: Penerbit Buku Kedokteran EGC

Lewa A.F., Pramantara D.P dan Rahayujati B. (2010). Faktor-Faktor Risiko Hipertensi Sistolik Terisolasi pada Lanjut Usia. Jurnal Berita Dokter Kesehatan, 26(4)

Martini, F. (2011). Fundamentals of Anatomy \& Physiology. Seventh Edition. Pearson, Benjamin Cummings

Mateos-C'aceres PJ, Zamorano-Le JJ, Rodr' 1guez-Sierra P,CarlosMacaya, L'opezFarr'e AJ. (2012). New and Old Mechanisms Associated with Hypertension in the Elderly. International Journal of Hypertension, 1-10. http://scihub.tw/10.1155/2012/150107

Muttaqin, A. (2010). Asuhan Keperawatan dengan Gangguan Kardiovaskuler. Jakarta: Salemba Medika

Narayan, S, Anant. (2013). Assessment of the Effects of Alternate Nostril Breathing on the Parasympathetic Nervous System in Young Adults. JCDR. DOI: 10.7860/JCDR/2013/4750.2948 pada tanggal 26 Februari 2018

Potter \& Perry. (2010). Fundamental Keperawatan. Buku 2 Edisi 7. Jakarta: Salemba Medika

Price, S. \& Wilson M. L. (2013). Patofisiologi. Konsep Klinis Proses-proses Penyakit. Edisi 6 Volume 1. Jakarta: EGC

Riskesdas. (2013). Riset Kesehatan Dasar. Diambil Kembali dari Kementerian Kesehatan Republik Indonesia. Badan Penelitian dan Pengembangan Kesehatan: www.depkes.go.id/resources/download/general/Hasil\%20Riskesdas\%202013.pdf pada tanggal 20 Maret 2018

Sheerwood, L. (2016). Fisiologi Manusia dari Sel ke Sistem. Edisi 8. Jakarta: Penerbit Buku Kedokteran EGC

Singalingging, G. (2011). Karakteristik Penderita Hipertensi di Rumah Sakit Umum Herna Medan 2011. Medan: 1-6

Siringiringo, M., Hiswani., Jemadi. (2013). Faktor-Faktor yang Berhubungan dengan Hipertensi pada Lansia Di Desa Sigaol Simbolon Kabupaten Samosir Tahun 2013. Diambil kembali dari https://jurnal.usu.ac.id/gkre/article/view/5179/2786 pada tanggal 4 Agustus 2017

Smeltzer, S., C. \& Bare, B., G. (2013). Buku Ajar: Keperawatan Medikal Bedah Brunner \& Suddarth. Jakarta: EGC 
Telles, S. (2012). Blood Pressure and Purdue Pegboard Scores in Individuals with Hypertension After Alternate Nostril Breathing, Breath Awareness and No Intervention. Medical Science Monitor, 19, 61-66. http://dx.doi.org/10.12659/MSM.883743np pada tanggal 27 Februari 2018

Tomasz, D., Grzegorz, B., Dorota, D. D., Marek. K., Gabriella., M., Grzegorz, K, Katarzyna, S., Agnieszka, B., Danuta, C, Gianfranco, P., \& Kalina KaweckaJaszcza. (2015). Blood Pressure Changes in Patients with Chronic Heart Failure Undergoing Slow Breathing Training. http://www.tandfonline.com/doi/abs/10.3109/08037051.2016.1099800?journalCo de=iblo20 pada tanggal 30 Oktober 2017

Wahyuni, N. (2015). Perbedaan Efektifitas Progressive Muscle Relaxation dengan Slow Deep Breathing Exercise terhadap Penurunan Tekanan Darah pada Hipertensi Derajat $\quad$ di Kota http://erepo.unud.ac.id/5118/1/80dff7664e736005eedc12d69d5c52ac.pdf pada tanggal 18 Maret 2018

WHO. (2013). A Global Brief on Hypertension. Silent Killer, Global Public Health Crisis. World Health Organization: http://ish-world. com/downloads/pdf/global_brief_hypertension. pdf pada tanggal 15 Maret 2018

WHO. (2013). High Blood Pressure, Global and Regional Overview. Diambil kembali dari World Health Organization. World Health Day: http://www.searo.who.int/entity/world_health_day/leaflet_burden_hbp_whd2013. pdf?ua=1 pada tanggal 15 Maret 2018

WHO. (2017). Noncommunicables Disease. Diambil kembali dari World Health Organization: http://www.who.int/mediacentre/factsheets/noncommunicablediseases/en/ pada tanggal 12 Agustus 2018 